\title{
"Sssuu Sssuu Suut Suut Suutr" e outras meditações poéticas de Chögyam Trungpa Rinpoche
}

Guilherme Gontijo Flores

Resumo: O presente artigo apresenta traduções poéticas de três poemas anglófonos do poeta Chögyam Trungpa Rinpoche (1939-1987) em sua confluência entre o experimento sonoro de "Sutra" ("Sutra") e o lamento religioso afetivo de "Expose" ("Expor"). As traduções são acompanhadas de algumas notas, bem como de uma breve apresentação de Chögyam Trungpa, que nasceu no Tibete independente em 1939 e faleceu no exílio em 1987.

Palavras-chave: Chögyam Trungpa Rinpoch; monasticismo; organização rítmica; tradução poética

\begin{abstract}
This article presents poetic translations of three Anglophone poems of Chögyam Trungpa Rinpoche (1939-1987) in their confluence between the sound experiment of "Sutra" ("Sutra") and the affective religious lament of "Expose" ("Expor"). The translations are accompanied by annotations as well as brief background of Chögyam Trungpa, who was born in independent Tibet in 1939 and died in exile in 1987.
\end{abstract}

Keywords: Chögyam Trungpa Rinpoche; monasticism; rhythmic organization; poetic translation 


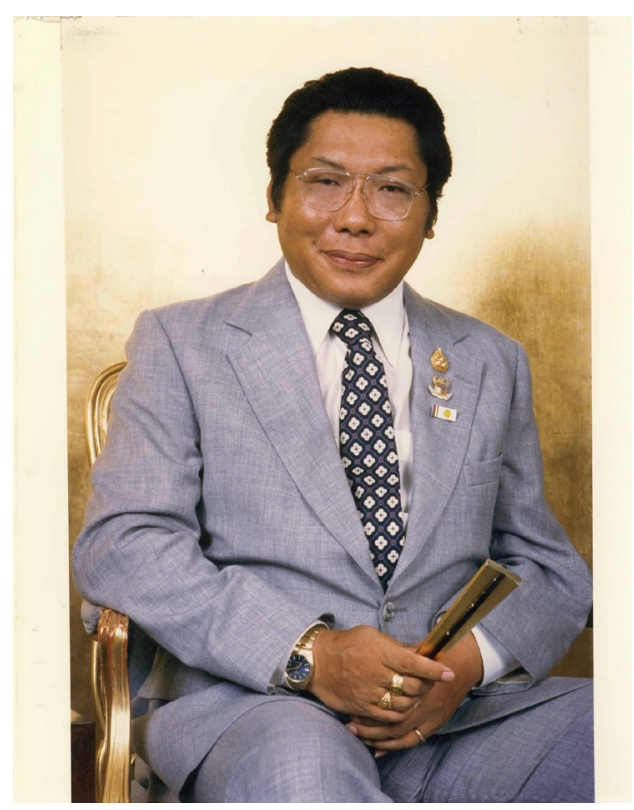

\section{Breve nota biográfica}

Chögyam Trungpa Rinpoche (1939-1987) nasceu na província de Kham, no Tibete Oriental; com apenas treze meses de idade, foi reconhecido como a décima primeira reencarnação da linhagem dos Trungpa tulku; assim, foi desde logo educado nos estudos e práticas budistas. Aos cinco anos, foi coroado como abade dos monastérios de Surmang, no Tibete, e teve um papel central na transmissão do budismo tibetano no Ocidente.

Depois de passar os anos de 1959 a 1963 na Índia, em seguida passou uma década no Reino Unido, depois um dos primeiros professores budistas tibetanos a vir aos Estados Unidos, ele fundou a Naropa Unuversity em Boulder, Colorado, e uma organização com cerca de 200 centros de meditação mundialmente conhecidos, tal como Shambhala International. Além dos seus livros de grandes vendas sobre ensinamentos budistas (Cutting Through Spiritual Materialism, The Myth of Freedom, Shambhala: The Sacred Path of the Warrior etc.), ele também escreveu poesia em tibetano e inglês e foi o primeiro tibetano no exílio a publicar um livro inteiro de poesia em inglês. Em 1986, sofreu uma parada cardíaca e veio a falecer em 4 de abril de 1987, em Halifax. 
É frequentemente chamado de Chögyam Trungpa Rinpoche, sendo a palavra tibetana rinpoche ("joia preciosa") um título honorrífico muitas vezes concedido aos líderes budistas tibetanos.

\section{Sobre a tradução}

A ideia de traduzir estes poemas veio de um gentil convite de Shelly Bhoil, que me apresentou os poemas de Chögyam Trungpa Rinpoche, que eu até então desconhecia. Trata-se de uma poesia ao mesmo tempo direta e reta, por um lado, e imagética e afetivamente muito densa, por outro. Todos eles são tirados do livro Timely Rain: Selected Poetry of Chögyam Trungpa (Shambhala Publications, 1998), com obras escritas em inglês, pois não tenho qualquer conhecimento da língua coloquial ou poética tibetana. Felizmente, Trungpa, como já se disse, produziu muitos poemas em inglês. Como é possível perceber, sua linguagem evita floreios verbais e complexidades sintáticas inesperadas; concentra-se, em vez disso, em desenvolver imagens mentais condensadas que, por sua vez, traduzem experiências intensas, algumas religiosas, outras demasiadamente humanas. Nesse sentido, explicitam a contradição de viver o ensinamento budista in nuce, porém com a fragilidade e precariedade da abertura ao desejo, à amizade, à saudade; sua própria vida foi marcada pela renúncia aos votos monásticos para ter uma vida sexual e também por adesão (talvez de fato excessiva) de tabaco e álcool; assim é que Trungpa captura seu leitor, mesmo aquele que não se interessa diretamente por budismo.

Como tradutor, busquei recriar um pouco dessa dureza de linguagem, desse gaguejar na língua segunda que permeia os poemas, como que evitando uma ânsia formalista por excesso de melopeia que desvirtuaria as potencialidades aqui em jogo. Em outras palavras,neste caso, a tradução poética não é aquela que tenta poetizar ao máximo (no sentido algo banal de embelezar e ornar os poemas), mas sim aquela que busca o movimento discurso de uma poeticidade contida em sua formalidade. 


\section{Tradução}

\section{A flower is always happy}

A flower is always happy because it is beautiful.

Bees sing their song of loneliness and weep.

A waterfall is busy hurrying to the ocean.

A poet is blown by the wind.

A friend without inside or outside

And a rock that is not happy or sad

Are watching the winter crescent moon

Suffering from the bitter wind.

\section{Uma flor sempre está feliz}

Uma flor sempre é feliz porque bela.

Abelhas cantam de pranto e solidão.

Uma cachoeira se ocupa em correr ao mar.

Um poeta é soprado pelo vento.

Um amigo sem dentro ou fora

E uma pedra nem alegre nem triste

Encaram a lua crescente de inverno

Sofrendo pelo amargo vento.

Em nome de certa concisão, optei por evitar o poliptoto de sing e song, no segundo verso, bem como aproximar a ideia de loneliness e weep, criando o sintagma "cantam de pranto de solidão". Isso talvez possa servir como exemplo aqui selecionado para uma série de soluções de ordem similar que revelam o que estou chamando de tradução poética apesar do desapego formalista comumente associado. Não pode se tratar, afinal, de mera transposição semântica, mas de certa escuta da organização rítmica (tal como a pensa Henri Meschonnic) do sujeito no discurso. Por outro lado, optei por uma inversão da ordem substantivo-adjetivo no último verso, produzindo "amargo vento", para garantir que as duas estrofes terminem com o vento a soprar, a cada momento num tom muitíssimo diferente. 


\section{Expose}

Acknowledging Accusations in the Name of Devotion

Remember, O Tusum Khyenpa!

Remember, O Father Karma Pakshi!

Remember, O Tilopa!

Remember, O Naropa!

Remember, O Milarepa!

Remember, O Marpa Lotsawa!

When I remember your kindness and your power,

I am left in the midst of the dark-age dungeon.

When I taste your great bliss

It is as if for the first time,

As if no one had tasted honey before.

When I realize your devotion,

It makes me so lonely.

When I see and experience anything good and wonderful,

It reminds me of the Kagyu wisdom and what you have sacrificed for us.

When I put on good clothing or see an attractive maiden,

When I handle gold or diamond,

I feel great pain and love for your wisdom and exertion.

I can only cry,

Your beauty and exertion and footprints make me so sad and full of longing,

Because we are left behind, nowhere,

Unable even to see your footprints in the dust.

How could you do such a thing?

Any mark of elegance or imprint of goodness,

For that matter, anything wicked and raw, confused or destructive,

Anything we see makes us feel so sad.

We will cry after the Father Kagyu.

Whether we are attacked or praised,

We do not follow the conventional pattern of hope and fear.

Nonetheless, you left us alone.

We feel so sad and lonely.

We want to taste you, smell you -

Where are you?

We cry and we would like to threaten you and say:

Show us your true face, to help us never give up! 
In this very bed, on this very cushion, in this very room -

If you don't show us your face and tell us,

We will perish in tears and dissolve in misery!

Please come and be with us.

At least look at us the way we are,

Which may not be the best you expect of us,

But we have the greatest devotion,

Beyond your preconceptions.

We will cry and shed our tears until our eyeballs drop in the sand dune

And we drown in the ocean of our tears.

O Knower of the Three Times, omniscient,

We have tried and practiced after your example:

Please don't give up.

When we iron our clothes, it is for you.

When we shine our shoes, it is for you.

When we wear jewelry, it is for you.

We do everything because of you;

We have no personal concern.

If we do not realize your dignity and wisdom,

May we rot and dissolve into dust.

We do everything for your sake and because of you.

We are so sad because of you.

We are so joyful because of you.

Father, if you have strength, this is the time to manifest.

I am about to die

And be reborn in crying and laughing at the same time.

Father, please have consideration for us.

We do not do anything for our own sake.

We do everything for the sake of devotion to you. 


\section{Expor}

Reconbecendo acusações em nome da devoção

Lembra-te, Tusum Khyenpa!

Lembra-te, Pai Karma Pakshi!

Lembra-te, Tilopa!

Lembra-te, Naropa!

Lembra-te, Milarepa!

Lembra-te, Marpa Lotsawa!

Quando me lembro de tua bondade e poder,

Sou deixado na masmorra da idade das trevas.

Quando provo tua grande bênção,

É como pela primeira vez,

Como se ninguém antes tivesse provado mel.

Quando compreendo a tua devoção,

Isso me deixa bem sozinho.

Quando vejo e vivo algo bom e maravilhoso,

Isso me lembra da sabedoria Kagyu e do que por nós sacrificaste.

Quando visto roupas boas ou vejo uma moça atraente,

Quando mexo com ouro ou diamante,

Sinto muita dor e amor por tua sabedoria e empenho.

Só posso chorar,

Tua beleza e empenho e pegadas me deixam bem triste e saudoso,

Porque ficamos para trás, em lugar nenhum,

Incapazes até de ver tuas pegadas no pó.

Como pudeste fazer isso?

Qualquer marca de elegância ou traço de bondade,

Por falar nisso, tudo de mau e bruto, confuso ou destrutivo,

Tudo o que vemos nos deixa bem tristes.

Vamos chorar pelo Pai Kagyu.

Quer nos ataquem ou louvem,

Não seguimos o padrão convencional de esperança e medo.

No entanto, deixaste-nos sozinho.

Estamos tão tristes e solitários. 
Queremos provar-te, cheirar-te -

Onde estás?

Choramos e queríamos te ameaçar e dizer:

Mostra a verdadeira face, ajuda a nunca desistirmos!

Nesta cama, nesta almofada, neste quarto -

Se não nos mostrares a face e contares,

Pereceremos em pranto e dissolvidos na miséria!

Por favor, vem e sê conosco.

Ao menos contempla-nos tal como somos,

Que talvez não seja melhor do que esperas,

Mas temos a maior devoção,

Além de teus preconceitos.

Vamos chorar e derramar o pranto até que olhos caiam na duna de areia

E nos afoguemos no mar de lágrimas.

Ó Conhecedor dos Três Tempos, onisciente,

Ensaiamos e agimos segundo teu exemplo:

Por favor, não desistas.

Quando passamos as roupas, é por ti.

Quando engraxamos os sapatos, é por ti.

Quando usamos joias, é por ti.

Fazemos tudo só por ti;

Não temos anseio pessoal.

Se não compreendemos tua dignidade e sabedoria,

Podemos apodrecer e nos dissolver em pó.

Fazemos tudo por tua causa e só por ti.

Estamos tão tristes só por ti.

Estamos tão felizes só por ti.

Pai, se tiveres força, agora é hora de manifestares.

Estou prestes a morrer

E renascer chorando e rindo ao mesmo tempo.

Pai, por favor, tem consideração por nós.

Não fazemos nada por nós mesmos.

Fazemos tudo por só por devoção a ti. 
Optei neste caso pelo pronome pessoal tu para tentar elevar o tom da linguagem ao efeito de luto e desamparo, ao mesmo tempo em que se constrói o afeto também religioso. Com intuito similar, porém agora para reforçar certa dureza no trato linguístico e as verdadeiras marteladas sintáticas das repetições de you, que acabei desdobrando em tu, te, ti.

\section{Sutra}

Sssuu Sssuu Suut Suut Suutr

Suutr Sutra Suuutra Sutruum

Suutuuom Suutrii Suutro-II

Ou Ai Oh Oh Ai Oh Ii

Suuuudj Suuuudj

Junção

Sutra Junção Junção Junção

Junção Junção

Confluência União Unida

Unificada

Unida Unificada Junção de Confluência

Unida Unificada Junção de Sutra

\section{Sutra}

Sssoo Sssoo Soot Soot Sootr

Sootr Sutra Soootra Sutroom

Sootroom Sootree Sootro-EE

Oo Ay Ob Ob Ay Ob Ee

Soooodj Soooodj

Junction

Sutra Junction Junction Junction

Junction Junction

Confluence Union United

Unified

United Unified Junction of Confluence

United Unified Junction of Sutra 
O poema acima faz um movimento duplo: por um lado desdobra a sonoridade da palavra sânscrita sutra na grafia do inglês (donde ssoo e soootra, por exemplo), o que pode servir para representar algo figurativamente o sentido do termo como "fio puro"; por outro lado, na segunda metade do poema, Trungpa constrói um significado implícito de sutra como um tipo de aforismo sobre união ou junção (através da meditação ou imersão no momento, como o som das letras) produzindo uma confluência poética e ética.

\section{Referências bibliográficas}

MESCHONNIC, Henri. Poética do tradu₹ir. Trad. Jerusa Pires Ferreira e Suely Fenerich. São Paulo: Perspectiva, 2010.

TRUNGPA, Chögyam. Timely Rain: Selected Poetry of Chögyam Trungpa Boston: Shambhala Publications, 1998.

Guilherme Gontijo Flores (Brasília, 1984) é poeta, tradutor e professor de Latim na UFPR. É autor dos poemas de carvão ::capim (2017/2018) e Todos os nomes que talvez tivésemos (2020), do romance História de Joia (2019) e dos ensaios Algo infiel (2017, em parceria com Rodrigo Tadeu Gonçalves e fotos de Rafael Dabul) e $A$ mulher ventriloquada (2018) . Publicou traduções de $A$ anatomia da melancolia, de Robert Burton (2011-2013, 4 vols.), Elegias de Sexto Propércio (2014), Safo: fragmentos completos (2017), Epigramas de Calímaco (2018) e Arte poéiica de Horácio (2020), entre outros. É coeditor da revista escamandro: poesia tradução crítica e membro fundador do grupo Pecora Loca, dedicado a tradução em performance. 